Pacific Journal of Mathematic 


\title{
DISTRIBUTION OF ROUND-OFF ERRORS FOR RUNNING AVERAGES
}

\author{
R. E. Greenwood and A. M. Gleason
}

1. Statement of the problem. Let $G_{1}, G_{2}, \ldots$ be scores (positive integers) obtained in a sequence of plays in a certain game. For purposes of handicapping matches it is desired to use running averages, and on the hypothesis that the score of the last play is more significant than any prior score, the following formula is used for computing the running averages $\left\{S_{n}\right\}$ :

$$
S_{n+1}=\frac{(k-1) S_{n}+G_{n+1}}{k}
$$

where $k$ is a positive integer. Certain modifications in (1.1) may be necessary when $n<k$.

The running averages defined by (1.1) are not necessarily integers. It is therefore convenient to define a rounded running average (which will be integral) by the relation

$$
T_{n+1}=\frac{(k-1) T_{n}+G_{n+1}+D}{k}
$$

It is convenient to use three set of values for $D$ in the foregoing relation.

Case A. For $k$ odd, $D=A \in\left\{\frac{-k+1}{2}, \frac{-k+3}{2}, \ldots, \frac{k-1}{2}\right\}$.

Case B. For $k$ even, $D=B \in\left\{\frac{-k}{2}+1, \frac{-k}{2}+2, \cdots, \frac{k}{2}\right\}$.

Case C. For $k$ even, $D=C \epsilon\left\{\frac{-k}{2}, \frac{-k}{2}+1, \ldots, \frac{k}{2}\right\}$.

For each $n \geq k$ define the error $E_{n}$ by the relation

Received July 21, 1952.

Pacific J. Math. 3 (1953), 605-611 


$$
E_{n}=T_{n}-S_{n}
$$

(For $n<k$, the error would depend on the modifications made in relation (1.1).) For $n \geq k$, then,

$$
E_{n+1}=T_{n+1}-S_{n+1}=\frac{(k-1) E_{n}+D}{k}
$$

For Case $\mathrm{A}$, if at some stage $\left|E_{n}\right| \leq(k-1) / 2$, then

$$
\left|E_{n+1}\right| \leq \frac{(k-1)(k-1) / 2+(k-1) / 2}{k}=\frac{k-1}{2} .
$$

For cases $\mathrm{B}$ and $\mathrm{C}$, if at some stage $\left|E_{n}\right| \leq k / 2$, then by a similar procedure one obtains

$$
\left|E_{n+1}\right| \leq k / 2 \text {. }
$$

Thus the errors introduced by the rounding off process are bounded if $\left|E_{k}\right| \leq$ $(k-1) / 2$ or $k / 2$ for the odd and even values of $k$ respectively.

It is assumed that the scores $\left\{G_{i}\right\}$ are such that equal probability values are realistic. In case $\mathrm{C}$, where there will sometimes be a choice for round-off, one might choose to round-off to the even integer. Thus, one would sometimes add $k / 2$ and sometimes subtract $k / 2$, corresponding to the two end-values with probabilities $1 /(2 k)$, while the intermediate values would have probabilities $1 / k$. It is desired to find a limiting distribution for the error $E_{n}$; in this paper such limiting distributions are found for a few special cases.

Allowing one's intuition free rein, one sees that limiting distributions for the error $E_{n}^{\prime}$ exist in all three cases. If such distributions exist, then relation (1.4) may be used to determine means and variances, if any. Thus

$$
\begin{aligned}
k_{\mu}\left(E_{n+1}\right) & =(k-1) \mu\left(E_{n}\right)+\mu(D), \\
k^{2} \operatorname{Var}\left(E_{n+1}\right) & =(k-1)^{2} \operatorname{Var}\left(E_{n}\right)+\operatorname{Var}(D) .
\end{aligned}
$$

It is easy to verify that

$$
\begin{aligned}
& \mu(A)=0, \quad \operatorname{Var}(A)=\left(k^{2}-1\right) / 12, \\
& \mu(B)=1 / 2, \quad \operatorname{Var}(B)=\left(k^{2}-1\right) / 12, \\
& \mu(C)=0, \quad \operatorname{Var}(C)=\left(k^{2}+2\right) / 12 \text {. }
\end{aligned}
$$

Then for the limiting distributions $E_{A}, E_{B}, E_{C}$ for the three cases one gets 
( 1.10$)$

$$
\begin{array}{ll}
\mu\left(E_{A}\right)=0, & \operatorname{Var}\left(E_{A}\right)=\left(k^{2}-1\right) / 12(2 k-1), \\
\mu\left(E_{B}\right)=1 / 2, & \operatorname{Var}\left(E_{B}\right)=\left(k^{2}-1\right) / 12(2 k-1), \\
\mu\left(E_{C}\right)=0, & \operatorname{Var}\left(E_{C}\right)=\left(k^{2}+2\right) / 12(2 k-1),
\end{array}
$$

2. Distribution of the round-off error for $k=2$, Case B. For the special value $k=2$ and for Case $\mathrm{B}$, one may take $E_{1} \equiv 0$. Let $F_{n}(x)$ be the cumulative distribution for $E_{n}$, and let $\left\{f_{i, n}\right\}$ be the jumps in $F_{n}(x)$ at the points of discontinuity. One readily obtains the functions

$$
\begin{gathered}
F_{2}(x)= \begin{cases}0, & x<0, \\
1 / 2, & 0 \leq x<1 / 2 \\
1, & 1 / 2 \leq x .\end{cases} \\
\left\{f_{i, 2}\right\}=\{1 / 2 \text { at } 0,1 / 2 \text { at } 1 / 2\} . \\
F_{3}(x)=\left\{\begin{array}{ll}
0, & x<0, \\
j / 4, & (j-1) / 4 \leq x<j / 4 \\
1,3 / 4 \leq x .
\end{array} \quad(j=1,2,3),\right. \\
\left\{f_{i, 3}\right\}=\{1 / 4 \text { at } 0,1 / 4 \text { at } 1 / 4,1 / 4 \text { at } 1 / 2,1 / 4 \text { at } 3 / 4\} .
\end{gathered}
$$

By induction one gets

$$
\begin{aligned}
& F_{n+1}(x)=\left\{\begin{array}{l}
0, x<0 \\
j / 2^{n},(j-1) / 2^{n} \leq x<j / 2^{n} \\
1,\left(2^{n}-1\right) / 2^{n} \leq x .
\end{array} \quad\left(j=1, \cdots, 2^{n}-1\right),\right. \\
& \left\{f_{i, n+1}\right\}=\left\{\text { jumps of } 1 / 2^{n} \text { at points } j / 2^{n}, j=0,1, \cdots, 2^{n}-1\right\} .
\end{aligned}
$$

In this simple example, heuristic considerations suggest that there is a limiting cumulative distribution function

$$
F(x)=\left\{\begin{array}{l}
0, x<0, \\
x, 0 \leq x<1, \\
1,1 \leq x,
\end{array}\right.
$$

and its associated distribution function

$$
f(x)= \begin{cases}1, & 0<x<1 \\ 0 & \text { elsewhere }\end{cases}
$$


In order to deal with continuous functions insofar as possible, it is convenient to take Fourier transforms of the jumps $\left\{f_{j, n}\right\}$. The finite Fourier transform may be defined by relations

$$
\begin{aligned}
\phi_{n}(u) & =\int_{-\infty}^{\infty} e^{i u t} d F_{n}(t) \\
& =\sum_{\text {all } j} f_{j, n} \exp (i u j) .
\end{aligned}
$$

Thus we get

$$
\begin{aligned}
& \phi_{2}(u)=1 / 2+(1 / 2) \exp (i u / 2) \\
& =\exp (i u / 4) \cos (u / 4)=\frac{1}{2} \exp (i u / 4) \frac{\sin (u / 2)}{\sin (u / 4)}, \\
& \phi_{n+1}(u)=\frac{1}{2^{n}} \sum_{j=0}^{j=2^{n}-1} \exp \left(\frac{i j u}{2^{n}}\right) \\
& =\frac{1}{2^{n}} \frac{1-\exp (i u)}{1-\exp \left(i u / 2^{n}\right)} \\
& =\frac{1}{2^{n}} \frac{\sin (u / 2)}{\sin \left(u / 2^{n+1}\right)} \exp \left(i u \frac{2^{n}-1}{2^{n+1}}\right) .
\end{aligned}
$$

The sequence of transforms $\left\{\phi_{n}\right\}$ has a limit $\phi(u)$,

$$
\phi(u)=\frac{\sin u / 2}{u / 2} \exp (i u / 2) .
$$

In order to transform back, it is convenient to use another definition of the Fourier transform,

$$
\phi(u)=\int_{-\infty}^{\infty} e^{i u t} f(t) d t .
$$

Then, whenever $f(x)$ is of class $L_{2}(-\infty, \infty)$ and of bounded variation in the neighborhood of $t[1, \mathrm{p} .83$, Theorem 58],

$$
\frac{1}{2}[f(t+0)+f(t-0)]=\lim _{\lambda \rightarrow \infty} \frac{1}{2 \pi} \int_{-\lambda}^{\lambda} e^{-i u t} \phi(u) d u .
$$

Direct computation of the inverse transform (using 2.11) of $\phi(u)$ as defined 
by (2.9) might be troublesome. However, the Fourier transform (2.10) of the supposed limiting distribution function of (2.5)

$$
f(x)= \begin{cases}1, & 0<x<1 \\ 0 & \text { elsewhere }\end{cases}
$$

is just the limiting function $\phi(u)$ as given by (2.9). Since $f(x)$ is of class $L_{2}(-\infty, \infty)$ and is of bounded variation, the theorem quoted above enables one to identify (2.5) as the limiting distribution function of the error for Case B, except for the values $f(0)$ and $f(1)$ where $f$ should be chosen as $1 / 2$.

The use of the Fourier transform $\phi_{n}(u)$, (as defined by $(2.6)$ ), is equivalent to the use of the characteristic functions of the jump distributions $\left\{f_{j, n}\right\}$. With this interpretation, it is possible to use Lévy's theorem [2, p. 101-102] to the effect that convergence of $\phi_{n}(u)$ to $\phi(u)$ implies the convergence of $F_{n}(x)$ to the limiting form $F(x)$ given by $(2.4)$ and that $\phi(u)$ is the characteristic function of the cumulative distribution function $F(x)$.

The mean and variance of $f(x)$ as given by (2.5) (with or without modifications at 0 and 1 ) are $1 / 2$ and $1 / 12$ respectively, and thus agree with the values called for by relations ( 1.10$)$.

3. Distribution of round-off errors for $k=2$, Case C. Case $\mathrm{C}$ has symmetry noticeably lacking in Case B. For convenience, take $E_{1} \equiv 0$ as before. Let $G_{n}(x)$ and $\left\{g_{j, n}\right\}$ be the cumulative and point-wise distribution functions. For this case

$$
\begin{aligned}
& G_{2}(x)= \begin{cases}0, & x<-1 / 2, \\
1 / 4, & -1 / 2 \leq x<0, \\
3 / 4, & 0 \leq x<1 / 2, \\
1, & 1 / 2 \leq x,\end{cases} \\
& \left\{g_{j, 2}\right\}=\{1 / 4 \text { at }-1 / 2,1 / 2 \text { at } 0,1 / 4 \text { at } 1 / 2\} .
\end{aligned}
$$

Designate the finite Fourier transform $(2.6)$ by $\psi_{2}(u)$. Then

$$
\begin{aligned}
\psi_{2}(u) & =(1 / 4) \exp (-i u / 2)+1 / 2+(1 / 4) \exp (i u / 2) \\
& =(1 / 4)[\exp (i u / 4)+\exp (-i u / 4)]^{2}=\cos ^{2}(u / 4)
\end{aligned}
$$

This may be written in the form

$$
\psi_{2}(u)=(1 / 4)[x+1 / x]^{2} \quad \text { where } \quad x=\exp (i u / 4)
$$


Notice that to get $\left\{g_{j, 3}\right\}$ from $\left\{g_{j, 2}\right\}$ and the set $\{C\},\{C\}=\{-1,0,1\}$ with probabilities $\{1 / 4,1 / 2,1 / 4\}$ respectively, one merely takes $1 / 4$ of the set $\left\{g_{j, 2}\right\}$ on a smaller range at one end of the new range, $1 / 2$ of the set $\left\{g_{j, 2}\right\}$ on a smaller range at the middle, and $1 / 4$ of the set $\left\{g_{j, 2}\right\}$ on a smaller range at the other end of the new range. In effect, one goes from $\psi_{2}(u)$ to $\psi_{3}(u)$ by replacing $x$ by $x^{2}$, multiplying by

$$
\left[(1 / 4) x^{2}+1 / 2+1 /\left(4 x^{2}\right)\right]=(1 / 4)[x+1 / x]^{2} .
$$

and then identifying $x=\exp (i u / 8)$.

By this rule, one gets

$$
\psi_{3}(u)=(1 / 4)^{2}(x+1 / x)^{2}\left(x^{2}+1 / x^{2}\right)^{2}=\cos ^{2}(u / 4) \cos ^{2}(u / 8) .
$$

Proceeding by induction, one gets

$$
\psi_{n+1}(u)=\cos ^{2}(u / 4) \cos ^{2}(u / 8) \cdots \cos ^{2}\left(u / 2^{n+1}\right) .
$$

The sequence of transforms $\left\{\psi_{n}(u)\right\}$ has a limit,

$$
\psi(u)=\lim _{n \rightarrow \infty} \psi_{n}(u)=\frac{\sin ^{2}(u / 2)}{(u / 2)^{2}} .
$$

by use of a well-known infinite product.

Direct computation of the inverse transform of (3.6) may be troublesome. However, it may be verified quite readily that if

$$
g(x)= \begin{cases}1+x, & -1<x<0, \\ 1-x, & 0 \leq x<1, \\ 0, & \text { elsewhere }\end{cases}
$$

the Fourier transform of $g(x)$ is just $\psi(u)$ of (3.6). Then, by use of (2.11), it follows that $g(x)$ as defined above may be taken as the pointwise distribution function for the limiting distribution $E_{C}$.

Direct computations show that

$$
\mu\left(E_{C}\right)=0, \quad \operatorname{Var}\left(E_{C}\right)=1 / 6,
$$

which values are in agreement with relations (1.10).

4. Conclusion. For higher values of $k$, the limits of the Fourier transforms may be difficult to obtain. 
A somewhat more general problem would be to take

$$
S_{n+1}=\frac{(k-m) S_{n}+m G_{n+1}}{k}
$$

instead of (1.1), where $k$ and $m$ are both positive integers. In effect, however, this merely allows the $k$ in $(1.1)$ to be a positive rational number instead of a positive integer.

An equivalent statement of the problem would be to consider the distribution of $M(d)$, where

$$
M(d)=\frac{1}{k} \sum_{i=0}^{\infty} d_{i}\left(\frac{k-1}{k}\right)^{i},
$$

and where $\left\{d_{i}\right\}$ is selected from the set $D$ according to the value of $k$ and the end-point choice. For the expansion of $M(d)$ is

$$
M(d)=(1 / k)\left\{d_{0}+(k-1) / k\left\{d_{1}+(k-1) / k\left\{d_{2}+\cdots\right\}\right\}\right\},
$$

and this is just the scoring used in (1.4) but with reversed numerical ordering. Thus for $k=2$ and Case $B, M$ is uniformly distributed on $(0,1)$, while for Case C, $M$ has a house-top distribution on $(-1,1)$.

\section{REFERENCES}

1. E. C. Titchmarsh, Theory of Fourier integrals, 2nd edition, Oxford, 1948.

2. M. G. Kendall, The advanced theory of statistics, volume 1, 4th edition, London, 1948.

University of TeXas

HarVARD UNIVERSITY 



\section{PACIFIC JOURNAL OF MATHEMATICS}

\section{EDITORS}

\author{
R. M. BOEINSON \\ University of California \\ Berkeley 4, California \\ E. HewitT \\ University of Washington \\ Seattle 5 , Washington
}

\section{R. P. DILWOR TH}

California Institute of Technology

Pasadena 4, California

E. F. BECKENBACH

University of California

Los Angeles 24, California

\section{ASSOCIATE EDITORS}

$\begin{array}{ll}\text { H. BUSEMANN } & \text { P. R. HALMOS } \\ \text { HERBERT FFDERER } & \text { IIEINZ HOPF } \\ \text { MARSHALL IJALL } & \text { R. D. JAMES }\end{array}$

\author{
BøRGE JESSEN \\ PAUL LÉVY \\ GEORGE PÓLYA
}

\author{
J. J. STOKER \\ E. G. STR AUS \\ KÔSAKU YOSIDA
}

\section{SFONSORS}

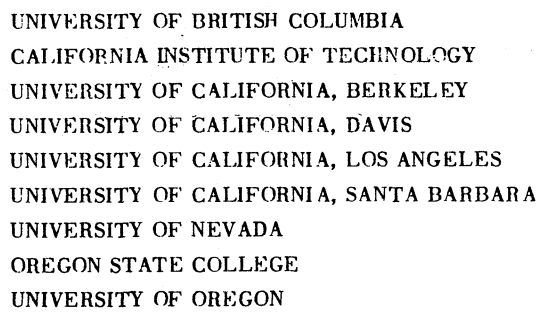

\author{
UNIVERSITY OF SOUTHERN CALIFORNIA \\ STANFORD RESEARCH INSTITUTE \\ STANFORD UNIVERSITY \\ WASHINGTON STATE COLLEGE \\ UNIVERSITY OF WASHINGTON \\ AMERICAN MATHEMATICAL SOCIETY \\ NATIONAL BUREAU OF STANDARDS, \\ INSTITUTE FOR NUMERICAL ANALYSIS
}

Mathematical papers intended for publication in the Pacific Journal of Mathematics should be typewritten (double spaced), and the author should keep a complete copy. Manuscripts may be sent to any of the editors except Robinson, whose term expires with the completion of the present volume; they might also be sent to M.M. Schiffer, Stanford University, Stanford, California, who is succeeding Robinson. All other communications to the editors should be addressed to the managing editor, E. F. Beckenbach, at the address given above.

Authors are entitled to receive 100 free reprints of their published papers and may obtain additional copies at cost.

The Pacific Journal of Mathematics is published quarterly, in March, June, September, and December. The price per volume (4 numbers) is $\$ 8.00$; single issues, $\$ 2.50$. Special price to individual faculty members of supporting institutions and to individual members of the American Mathematical Society: $\$ 4.00$ per volume; single issues, $\$ 1.25$.

Subscriptions, orders for back numbers, and changes of address should be sent to the publishers, University of California Press, Berkeley 4, California.

Printed at Ann Arbor, Michigan. Entered as second class matter at the Post Office, Berkeley, California.

\section{UNIVERSITY OF CALIFORNIA PRESS • BERKELEY AND LOS ANGELES}




\section{Pacific Journal of Mathematics}

\section{Vol. 3, No. 3 \\ May, 1953}

L. Carlitz, Some theorems on generalized Dedekind sums ............ 513

L. Carlitz, The reciprocity theorem for Dedekind sums ............. 523

Edward Richard Fadell, Identifications in singular homology theory..... . . 529

Harley M. Flanders, A method of general linear frames in Riemannian

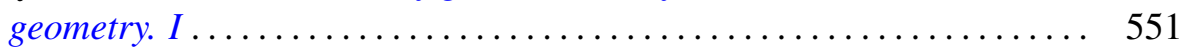

Watson Bryan Fulks, The Neumann problem for the heat equation ........ 567

Paul R. Garabedian, Orthogonal harmonic polynomials.............. 585

R. E. Greenwood and Andrew Mattei Gleason, Distribution of round-off errors for running averages .............................. 605

Arthur Eugene Livingston, The space $H^{p}, 0<p<1$, is not normable ... 613

M. N. Mikhail, On the order of the reciprocal set of a basic set of polynomials .......................................... 617

Louis Joel Mordell, On the linear independence of algebraic numbers . . . . 625

Leo Sario, Alternating method on arbitrary Riemann surfaces .......... 631

Harold Nathaniel Shapiro, Iterates of arithmetic functions and a property of the sequence of primes.............................. 647

H. Shniad, Convexity properties of integral means of analytic functions . . . . 657

Marlow C. Sholander, Plane geometries from convex plates ........... 667 